\title{
An Analysis of a Constant Current Controlled Bi- directional DC-DC Converter with Digital Control
}

\author{
Shingo Tachikawa ${ }^{1}$, Toshiro Hirose ${ }^{1,2}$, Hiroshige Yanagi $^{1}$, Yoichi Ishizuka ${ }^{1}$ and Hirofumi Matsuo ${ }^{1}$ \\ 1 Nagasaki University \\ 2 Nishimu Electronics Industries Co., Ltd. \\ E-mail: isy2@nagasaki-u.ac.jp
}

\begin{abstract}
This research aims at the development of switching power supply circuits that supply electric power from distributed power sources to electronic devices. A typical switching power supply uses constant voltage control, but in addition to constant voltage control, we propose constant current control enabled by means of digital PWM(pulse width modulation) control and a bidirectional DC-DC converter capable of converting energy in two directions using a single DC-DC converter [1-3].

This paper supposes that the aforementioned technology will be applied to streetlight systems that use solar cells, LEDs and batteries. Experiments on the charging operation using batteries and LEDs, as well as of the discharging operation using solar cells and batteries, were conducted, and this technology was evaluated based on those results.
\end{abstract}

\section{INTRODUCTION}

With the increased consumption of energy in recent years, attention has been drawn to distributed electric power sources such as photovoltaic and wind power generation, which are forms of green energy that do not emit carbon dioxide. Distributed electric power sources, as compared to large-scale centralized power generation, are characterized by having few location requirements, making them suitable for installation in the vicinity of a demand area, and being suitable for emergency use. Among these types of distributed electric power sources, the use of solar cells is assumed here. With solar cells, however, there arises a problem of nonuniform power output according to the season, weather or time zone, and a means to stabilize the power must be employed when used with electronic devices. For this purpose, switching power supplies are used because of their high efficiency and ability to handle a wide range of input voltage variations. Constant voltage control is generally used in a switching power supply, and depending on the application, overcurrent and constant current control may also be required.

With a solar cell, the point of maximum power fluctuates according to the voltage actually required by the object to be charged, i.e., a storage battery or load connected to the solar cell, and one characteristic of solar cells is their operation as a constant current source, whereby the output current is determined according to the fluctuation in the maximum power point. Consequently, output power can only be obtained at a lower level than the original rated output characteristic, and loss occurs at the maximum power point (MPP). In order to eliminate this loss, a maximum power point tracking (MPPT) control that performs bidirectional balancing is inserted between the solar cell and the load so that operation is always performed at the maximum power point, thereby enabling higher conversion efficiency and the output to be obtained as effective charging power [4]. This technique, however, looks to obtain a large power output from solar cells, and does not adequately consider the object to be charged. The control of the charging and discharging of batteries and the like is extremely important as it directly affects the service life of the batteries.

Here, we propose a constant current controlled bidirectional DC-DC converter using digital control, which resists deterioration with age and permits easy modification of the control, and which uses a common PWM control to output a constant current in response to bidirectional fluctuations in the input voltage and load.

Section 2 describes the various operating states of the proposed circuit, classified according to charge and discharge modes. Section 3 describes the proposed digital constant current control. Section 4 shows the results of discharge operation experiments using batteries and LEDs, and of charge operation experiments using solar cells and LEDs. Finally, Section 5 presents a discussion of our conclusion.

\section{II.DESCRIPTION OF CIRCUIT OPERATION}

Figure 1 shows proposed circuit. The circuit operations will be described below with distinguish the mode charge and discharge.

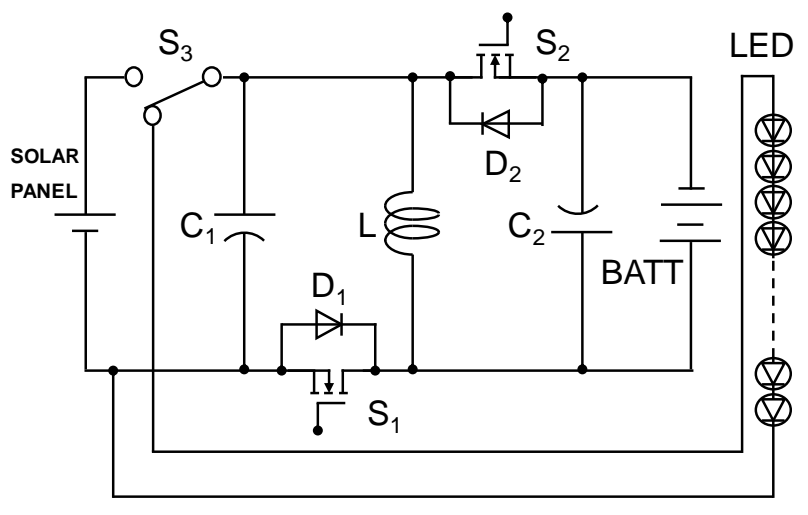

Fig.1 Proposed bidirectional DC-DC converter 


\section{A. Principles of operation during discharge mode.}

The various operating states shown in Figs. 2 and 3 are

(1) In STATE 1, switch S1 turns ON, switch S2 and diode D2 turn OFF, current flows from the input voltage Ei to inductor L, and magnetic energy is stored in the inductor.

(2) In STATE 2, switches S1 and S2 turn OFF, and the magnetic energy stored in inductor L flows through diode D2 and is released, generating output voltage Eo.

(3) In STATE 3, switch S1 turns OFF and switch S2 turns $\mathrm{ON}$, and the magnetic energy that had been flowing through diode D2 and was released instead flows through switch $\mathrm{S} 2$ and is released.

(4) After STATE 3, switches S1 and S2 turn OFF, and the magnetic energy that had been flowing through switch S2 instead flows through diode D2 and is released so that the operation becomes similar to that of STATE 2. The operation subsequently returns to STATE 1 .

\section{B. Principles of operation during discharge mode}

The discharge mode, similar to the charge mode, also has three operating states according to the ON/OFF combination of switches S1 and S2 and diode D1 as shown in Figs. 4 and 5.

(1) In STATE 4, switch S2 turns ON, switch S1 and diode D1 turn OFF, current iL flows from input voltage Ei to inductor $\mathrm{L}$, and magnetic energy is stored in inductor $\mathrm{L}$. Also, at this time, capacitor $\mathrm{C} 1$ discharges, and Eo is output.

(2) In STATE 5, switches S1 and S2 turn OFF, and the magnetic energy that had been stored in inductor L flows through diode D1 and is released, generating output voltage Eo.Also, at this time, capacitor $\mathrm{C} 1$ charges.
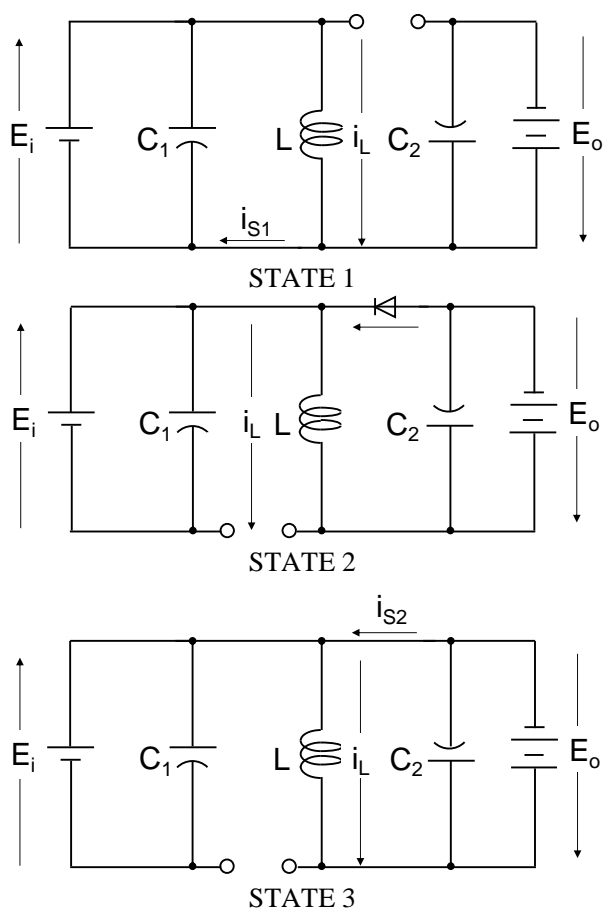

Fig.2 Equivalent circuits of charge mode.

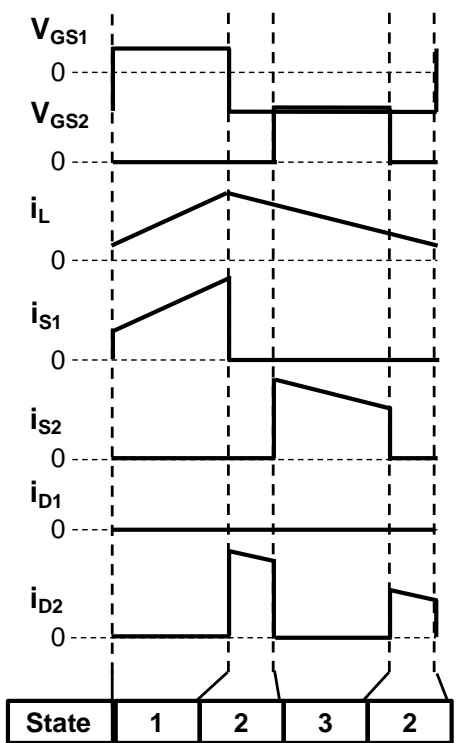

Fig.3. Theoretical waveforms of charge mode.

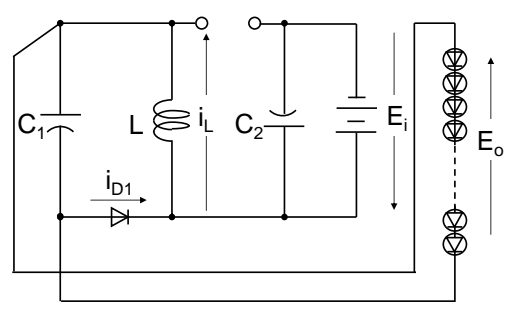

STATE 4

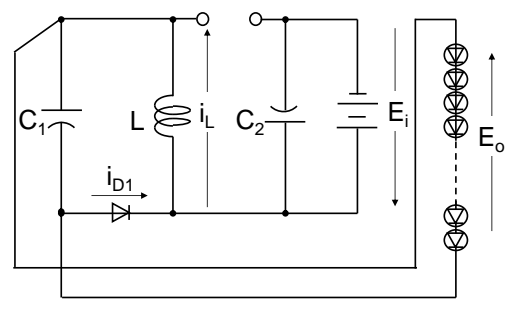

STATE 5

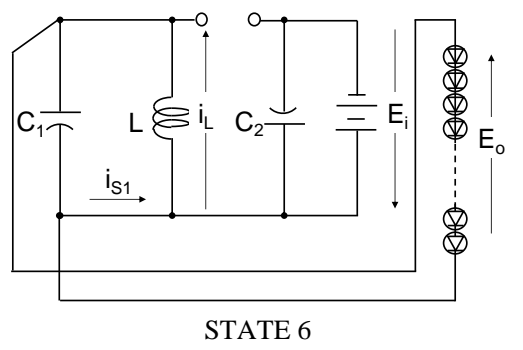

Fig. 4. Equivalent circuits of discharge mode.

(3) In STATE 6, switch S2 turns OFF, switch S1 turns ON, and the magnetic energy that had been flowing through diode D1 and released instead flows through switch S1 and is released. After STATE 6, switches S1 and S2 turn OFF and the magnetic energy that had been flowing through switch S1 instead flows through diode D1 and is released so that the operation becomes similar to that of STATE 5 . The operation subsequently returns to STATE 4. 


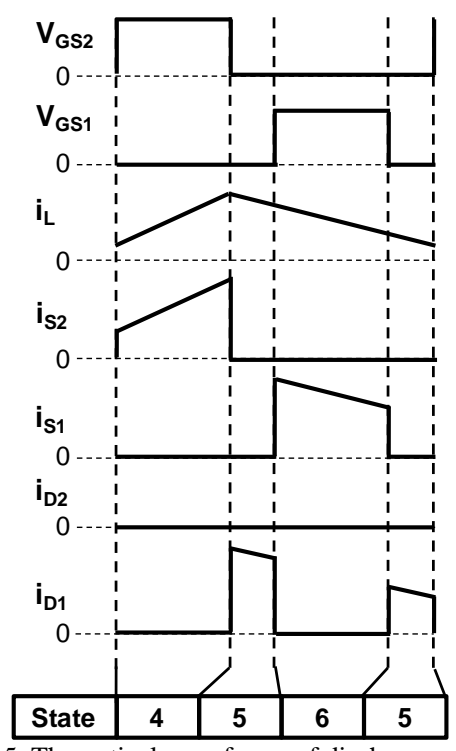

Fig. 5. Theoretical waveforms of discharge mode.

\section{CONSTANT CURRENT CONTROL METHOD}

The circuit shown in Figs. 6 and 7 consists of a bidirectional DC-DC converter unit, a detection resistor $\mathrm{R}_{\mathrm{d}}$, a control circuit and an NEC V853 microcontroller, whereby the output voltage dividing resistors $R_{1}$ and $R_{2}$ and the control circuit use the NEC V853 microcontroller. A characteristic of this circuit is that the potential difference $e_{s}$ between the detection resistor $R_{d}$ and the output voltage dividing resistors $R_{1}$ and $R_{2}$ is input into the control circuit to provide PWM control. Current control is influenced by the coefficient of variation $\mathrm{G}$ of the current as calculated according to Eq. (1). In a case where $G>1$, the current value will increase when the voltage value increases, and a fold-back type drooping characteristic will be exhi-

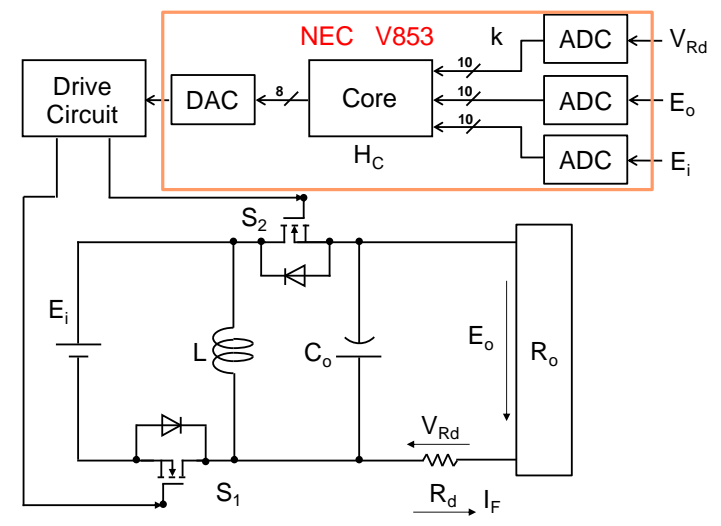

Fig. 6. Proposed digital control circuit configuration.

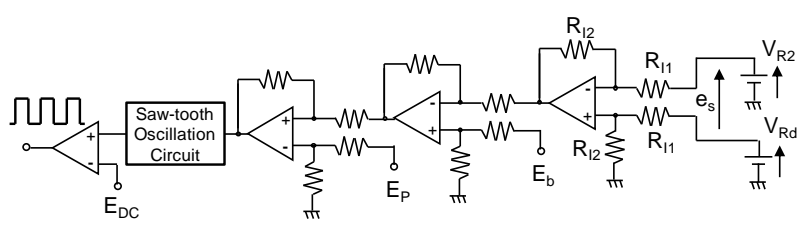

Fig. 7. Analogized equivalent circuit of Digital constant current. bited, if $\mathrm{G}<1$, the current will decrease when voltage increases and a voltage drooping characteristic will be exhibited, and if $G=1$, a constant current characteristic will be exhibited. Different $G$ values can be used as appropriate for the intended application. Here, in order to implement constant current control, the parameters are set so that $\mathrm{G}=1$, and the current is controlled to be constant in response to load fluctuations. In response to input fluctuations, constant current control is implemented by monitoring the input voltage $\mathrm{E}_{\mathrm{i}}$, and changing the value of the output voltage divider resistor $\mathrm{R}_{2}$, similar to a load fluctuation, such that the current coefficient of variation $\mathrm{G}$ of Eq. (1) is maintained at a value of 1.[1-3]

$$
G=E_{i} \cdot H_{C} \cdot \frac{R_{1}}{R_{1}+R_{2}}
$$

$\mathrm{H}_{\mathrm{c}}$ in Eq. (1) represents the current gain in the constant current control circuit, and is expressed by Eq. (2).

$$
H_{C}=-\frac{\frac{R_{l 2}}{R_{l 1}}}{E_{P}}
$$

The steady-state duty ratio $\mathrm{D}$ is expressed by Eq. (3).

$$
D=\frac{E_{b}-H_{C} \cdot e_{s}}{E_{b}-H_{C} \cdot e_{s}+1}
$$

$\mathrm{E}_{\mathrm{b}}$ in Eq. (3) represents the bias voltage and is expressed by Eq. (4).

$$
E_{b}=\frac{E_{\text {iref }} \cdot H_{C} \cdot e_{\text {sref }}+E_{\text {oref }}}{E_{\text {iref }}}
$$

\section{EXPERIMENTS}

The following experiments were conducted using the proposed digital control bidirectional DC-DC converter, a solar cell (PV130 W-DC, CCP-F45 module), LEDs (W4218) and a battery (GS YUASA, PE0.8).Circuit parameters are listed in Table 1.

\section{A. Discharging from battery to LED}

Using the battery as the input, constant current control was implemented and the LEDs were illuminated by the drive circuit.

When a certain forward voltage is applied to the LEDs, a forward current begins to flow, and this forward current increases with subsequent increases in the forward voltage. The brightness of the LED depends on the forward current, and as the output of a single LED is small, multiple LEDs must be connected to provide sufficient illumination for use in a lighting fixture. Therefore, to achieve a uniform output current, it is more effective to supply a constant current to the LEDs and use a series connection that eliminates brightness variations, rather than to use a circuit-compensating parallel connection. However, in the case where a series connection is used and an LED short-circuit failure occurs, the output voltage and output current will change. Accordingly, there is a need for constant current control that continuously supplies a 
Table 1

Circuit parameters

\begin{tabular}{|c|c|c|}
\hline & $\begin{array}{c}\text { Charge oper- } \\
\text { ation }\end{array}$ & $\begin{array}{c}\text { Discharge op- } \\
\text { eration }\end{array}$ \\
\hline $\begin{array}{c}\text { Drive reference current } \mathrm{I}_{\text {Fref }} \\
{[\mathrm{mA}]}\end{array}$ & 320 & 350 \\
\hline Switching frequency $\mathrm{f}_{\mathrm{s}}[\mathrm{kHz}]$ & \multicolumn{2}{|c|}{16} \\
\hline Resistance $\mathrm{R}_{\mathrm{d}}[\Omega]$ & 0.512 & 0.507 \\
\hline Choke inductor $\mathrm{L}[\mathrm{mH}]$ & \multicolumn{2}{|c|}{775} \\
\hline Output capacitor $\mathrm{C}_{\mathrm{o}}[\mu \mathrm{F}]$ & \multicolumn{2}{|c|}{2200} \\
\hline Resistance $\quad \mathrm{R}_{1}[\mathrm{k} \Omega]$ & \multicolumn{2}{|c|}{1} \\
\hline $\begin{array}{c}\text { Input reference voltage } \mathrm{E}_{\text {iref }} \\
{[\mathrm{V}]}\end{array}$ & 30 & 12 \\
\hline $\begin{array}{ll}\text { Output } & \text { reference voltage } \\
& \mathrm{E}_{\text {oref }}[\mathrm{V}]\end{array}$ & 12 & 18 \\
\hline $\mathrm{E}_{\mathrm{P}}[\mathrm{V}]$ & \multicolumn{2}{|c|}{-1} \\
\hline $\mathrm{E}_{\mathrm{DC}}[\mathrm{V}]$ & \multicolumn{2}{|c|}{1} \\
\hline Proportional gain $\mathrm{H}_{\mathrm{c}}$ & 2 & 5 \\
\hline $\mathrm{E}_{\mathrm{b}}[\mathrm{V}]$ & 0.32768 & 0.88275 \\
\hline $\mathrm{e}_{\text {sref }}[\mathrm{V}]$ & -0.03616 & -0.12255 \\
\hline Resistance $\mathrm{R}_{11}[\mathrm{k} \Omega]$ & \multicolumn{2}{|c|}{1} \\
\hline Resistance $\mathrm{R}_{12}[\mathrm{k} \Omega]$ & 2 & 5 \\
\hline
\end{tabular}

constant current, even if multiple LEDs fail, and that suppresses brightness variation.

In the discharge operation of this experiment, a fully charged battery and a drive circuit were used, and constant current control that targeted a value of $350 \mathrm{~mA}$ was implemented to illuminate the LEDs. The experiment was conducted with four batteries arranged in a parallel configuration and five LEDs connected in a series configuration. Figure 8 shows battery voltage and respective output current over time. Although the battery voltage dropped by $14.7 \%$, the drop in current was limited to $6.1 \%$ and the efficiency was $90.1 \%$. However, the average value of the output current was $308 \mathrm{~mA}$, which deviated by $12 \%$ from the target value. This deviation is thought to be attributable to the proportional control limit having been reached, switching loss, error in the microcontroller detection, and a future investigation of the control unit is necessary.

\section{B. Charging from solar cell to battery}

Using a solar cell, constant current control was performed to charge four batteries connected in a parallel configuration.

Battery-charging methods include constant voltage charging, constant current charging, constant voltage constant current charging. In all of these methods, overcharging of the battery must be prevented. In the constant voltage as well as the constant voltage constant current charging methods, as the charging process progresses and the charging voltage reaches a certain voltage, the charging current decreases to a minute level so that overcharging does not occur. Overcurrent protection is possible by means of the constant current control in the pro-

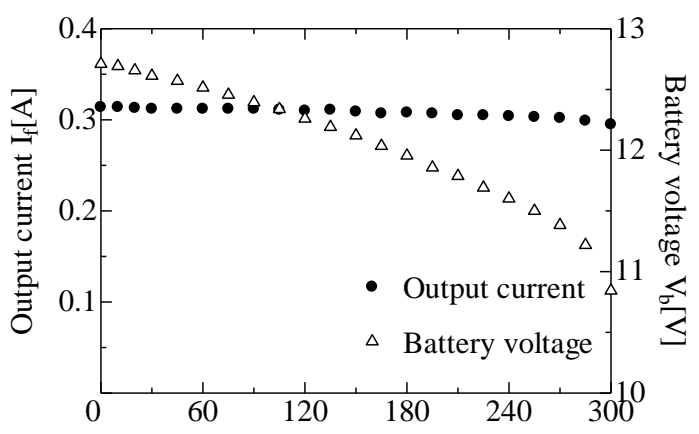

Elapsed time [min]

Fig. 8 Output current to LEDs, and battery voltage

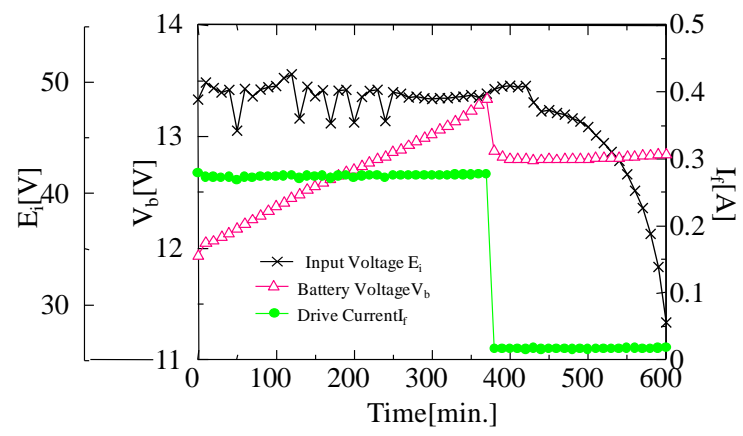

Fig. 9 Charge characteristic

posed circuit, but because the current does not decrease when a preset voltage level is reached, overcharging will occur. Therefore, overcharging protection is implemented by adding a control to monitor the battery-charging voltage and to reduce the current to a minute level when a preset voltage level has been reached.

Here, the experiment was conducted with digital control employed to reduce the current to a minute level when a battery-charging voltage of $13.65 \mathrm{~V}$ was reached, and the output current was set as $320 \mathrm{~mA}$. Figures 9 and 10 show that by controlling the input from the solar cell, the battery can be charged with a constant current. The variability of input voltage from the solar cell was $10 \%$ and the charging voltage variability was $11 \%$, but the variability of input current to the battery was limited to $2.9 \%$. Additionally, overcharging protection is provided by monitoring the battery-charging voltage, and reducing the current value to a minute level when the battery-charging voltage reaches the vicinity of a preset voltage. However, the output current deviated from the targeted current value by $13 \%$, and in the monitoring of battery voltage, a microcontroller detection error occurred, with the changeover to a minute current level actually taking place at $13.34 \mathrm{~V}$ rather than at the preset voltage of $13.6 \mathrm{~V}$. The same can be said about these problems as was said about discharging, i.e. the control unit must be further investigated.

\section{CONCLUSION}

In this paper, a bidirectional DC-DC converter equipped with a digital constant-current control function was proposed, and experiments using solar cells, batteries and LEDs were carried out. 
The results can be summarized as follows.

In a discharge operation wherein series-connected LEDs are illuminated by discharge from a battery, brightness variations could be eliminated by performing constant current control.

In a charging operation wherein a battery is charged from a solar cell, current control was performed to provide overcurrent protection.

Overcharging protection was made possible by using digital control to limit the current according to the charging voltage.

Based on the above results, experiments performed using solar cells, batteries and LEDs with the proposed constant current controlled bidirectional DC-DC converter with digital control showed that constant current control was possible in both the charging and discharging directions. When charging the battery, overcharge protection was implemented by performing constant current control and switching the current to a minute level when a preset voltage is reached. However, the targeted current value was not achieved during discharging or charging, and the cause is thought to be attributable to the proportional control limit having been reached, switching loss, error in the microcontroller detection, and a future investigation of I-control and D-control for the control circuit is necessary. Furthermore, we plan to use multistage constant current charging as the battery-charging method in order to shorten the battery charging time and extend the cycle life.

\section{REFERENCES}

[1] M. Nishikawa, Y. Ishizuka, H. Matsuo, K. Shigematsu, "An LED Drive Circuit with Constant-Output-Current Control and Constant-Luminance Control", IEEE International Telecom-munications Energy Conference (Intelec'06), Providence, Rhode Island, September 10 - 14, pp. 90 95.2006

[2] K. Morihori, Y. Ishizuka, H. Matsuo, "Consideration of A Drive Circuit for LED with Constant-Current Control", IEICE Technical Report EE 2004-68(2005-02), pp.13-19, February, 2005.

[3] H. Yanagi, H. Toshiro, Y. Ishizuka, H. Matsuo, "A High Power LED Street Light System with Constant-Current Con-trol”, The Papers of Technical Meeting on "Electronic Cir-cuits",IEE Japan. ECT-09-029 Junary 21-23 2009.

[4] Y. Chen, K. Smedley, F. Vacher, J.Brouwer "A New Max-imum Power Point Tracking Controller for Photovoltaic Power Generation" Eighteenth Annual IEEE Applied Power Elec-tronics Conference And Exhibition(APEC2003) Session2 2.2, 9-13 February 2003. 